\title{
Alzheimer risk loci and associated neuropathology in a population-based study (Vantaa 85+)
}

Mira Mäkelä, MD, * Karri Kaivola, BM, * Miko Valori, MSc, Anders Paetau, MD, PhD, Tuomo Polvikoski, MD, PhD, Andrew B. Singleton, PhD, Bryan J. Traynor, MD, PhD, David J. Stone, PhD, Terhi Peuralinna, PhD,

Pentti J. Tienari, MD, PhD, Maarit Tanskanen, MD, PhD, and Liisa Myllykangas, MD, PhD

Neurol Genet 022018 vol. 4 no. 1 e211. doi:10.1212/NXG.0000000000000211

\section{Abstract}

\section{Objective}

To test the association of distinct neuropathologic features of Alzheimer disease $(A D)$ with risk loci identified in genome-wide association studies.

\section{Methods}

Vantaa $85+$ is a population-based study that includes 601 participants aged $\geq 85$ years, of which 256 were neuropathologically examined. We analyzed $29 \mathrm{AD}$ risk loci in addition to APOE \&4, which was studied separately and used as a covariate. Genotyping was performed using a single nucleotide polymorphism (SNP) array (341 variants) and imputation (6,038 variants). Participants with Consortium to Establish a Registry for Alzheimer Disease (CERAD) (neuritic A $\beta$ plaques) scores $0(n=65)$ vs score $M+F(n=171)$ and Braak (neurofibrillary tangle pathology) stages $0-$ II $(n=74)$ vs stages IV-VI $(n=119)$, and with capillary A $\beta$ (CapA $\beta$, $n=77)$ vs without $(n=179)$ were compared. Cerebral amyloid angiopathy (CAA) percentage was analyzed as a continuous variable.

\section{Results}

Altogether, 24 of the 29 loci were associated (at $p<0.05$ ) with one or more AD-related neuropathologic features in either SNP array or imputation data. Fifteen loci associated with CERAD score, smallest $p=0.0002122$, odds ratio (OR) 2.67 (1.58-4.49) at MEF2C locus. Fifteen loci associated with Braak stage, smallest $p=0.004372$, OR $0.31(0.14-0.69)$ at GAB2 locus. Twenty loci associated with CAA, smallest $p=7.17 \mathrm{E}-07, \beta 14.4(8.88-20)$ at CR1 locus. Fifteen loci associated with CapA $\beta$ smallest $p=0.002594$, OR $0.54(0.37-0.81)$ at HLA-DRB1 locus. Certain loci associated with specific neuropathologic features. CASS4, CLU, and ZCWPW1 associated only with CAA, while TREM2 and HLA-DRB5 associated only with CapA $\beta$.

\section{Conclusions}

$\mathrm{AD}$ risk loci differ in their association with neuropathologic features, and we show for the first time distinct risk loci for CAA and CapA $\beta$.
Correspondence

Dr. Myllykangas

liisa.myllykangas@helsinki.fi 


\section{Glossary}

$\mathbf{A} \beta=$ amyloid $-\beta ; \mathrm{AD}=$ Alzheimer disease $; A P O E=$ apolipoprotein $\mathrm{E} ; \mathrm{CAA}=$ cerebral amyloid angiopathy; CapA $\beta$ = capillary $\mathrm{A} \beta ; \mathrm{CERAD}=$ Consortium to Establish a Registry for Alzheimer Disease; Chr9 region = chromosome 9 region; CI = confidence interval; GWAS = genome-wide association study; IHC = immunohistochemistry; LOAD = late-onset Alzheimer disease; $\mathbf{O R}=$ odds ratio; $\mathbf{S N P}=$ single nucleotide polymorphism.

Late-onset Alzheimer disease (LOAD) is neuropathologically characterized by cerebral accumulation of amyloid- $\beta(A \beta)$ peptide containing neuritic plaques and hyperphosphorylated tau-protein, and by cerebral amyloid angiopathy (CAA) and capillary $\mathrm{A} \beta(\mathrm{CapA} \beta)$ deposition. LOAD is known to have a fairly strong hereditary risk, ${ }^{1}$ the apolipoprotein $\mathrm{E}(\mathrm{APOE}) \varepsilon 4$ being the strongest genetic risk factor. ${ }^{2,3}$ Recently, genome-wide association studies (GWASs) have identified approximately 30 Alzheimer disease $(\mathrm{AD})$-associated risk loci, ${ }^{4-10}$ which are known to encode proteins involved in immune system and inflammation (CLU, CR1, ABCA7, MS4A, CD33, EPHA1, MEF2C, HLA-DRB1/DRB5, TRIP4, and TREM2), cholesterol metabolism (APP, CLU, ABCA7, and SORL1), synaptic and membrane function (PICALM, BIN1, CD33, CD2AP, EPHA1, INPP5D, PTK2B, SORL1, and SLC2A4), tau pathology (BIN1), and $A \beta$ metabolism (APP, CLU, CR1, ABCA7, INPP5D, and SORL1). ${ }^{6,8,11-15}$ Most of the previous GWASs have been based on large clinically diagnosed hospital-based samples, ${ }^{5-10,14}$ but recently, a few GWASs have been published based on neuropathologically verified data sets. ${ }^{16}$ In those studies, $A B C A 7$ and $C D 2 A P$ as well as a variant near APP (rs2829887) and ABCG1, GALNT7 and an intergenic region on chr 9 (9: $129,280,000-129,380,000)$ loci have been found to be associated with neuritic plaque pathology., ${ }^{4,16}$ The Consortium to Establish a Registry for Alzheimer disease (CERAD) score and Braak stage have also been associated with ABCA7, BIN1, CASS4, MEF2C, and PICALM, and Braak stage with CLU, SORL1, ZCWPW1, and CERAD score with $M S 4 A 6 A$, and $C D 33{ }^{4}$

Here, we analyzed possible associations of $\mathrm{AD}$ risk loci with each neuropathologic feature (neuritic plaque, neurofibrillary tangle and CAA, and CapA $\beta$ ) in a population-based sample of very elderly Finns (Vantaa 85+ Study).

\section{Methods}

\section{Study population}

The Vantaa 85+ Study includes 601 individuals, aged at least 85 years, who were living in the city of Vantaa on April 1, 1991. Autopsy and neuropathologic examination were performed on 300 (mean age $92.4 \pm$ SD 3.7 years, range 85-105). The clinical characteristics of the whole genotyped subpopulation $(\mathrm{N}=512)$ and the whole genotyped neuropathologically examined subpopulation $(\mathrm{N}=300)$ are shown in table e-1 (http://links.lww.com/NXG/A16).

\section{Neuropathologic examination}

Evaluation of Braak stages of Alzheimer-type neurofibrillary pathology ${ }^{17}$ and CERAD scores of neuritic plaques ${ }^{18}$ have been described previously. ${ }^{19}$ The percentage of CAA-affected noncapillary blood vessels was estimated using histologic Congo red as described previously and confirmed by immunohistochemistry (IHC). ${ }^{20}$ The presence of CapA $\beta$ was analyzed as described before ${ }^{20,21}$ using IHC. $^{21}$

\section{Evaluation of the APOE genotype, SNP array, and candidate gene approach}

$A P O E$ genotyping was performed as described previously. ${ }^{22}$ A GWAS was conducted as previously described $^{23}$ by Infinium Human 370 BeadChips (Illumina, San Diego, CA) for 327,521 variants in blood samples from 512 participants. Data quality control was done using the standard PLINK v1.9 $9^{24,25}$ protocol. ${ }^{26}$ In summary, related individuals (identity by descent $>0.185$ ), individuals with discordant sex information, divergent ancestry, elevated missing data $(>3 \%)$ rate, or outlying heterozygosity rate $( \pm 2 \mathrm{SD})$ were excluded. Variants with missing per person rate $>10 \%$, minor allele frequency $<1 \%$ and missing data rate $>5 \%$, or significantly different genotype call rates between cases and controls $(p<0.00001)$ were excluded. Variants not in the Hardy-Weinberg equilibrium $(p<$ 0.00001 ) were also discarded.

A PubMed search was performed to identify all the loci that have been reported in previous GWAS analyses in samples from participants with clinically or neuropathologically diagnosed $\mathrm{AD}$. Besides $A P O E$, we found reports on 44 variants at 29 loci. Variants at genes near these candidate loci were extracted from the qualitycontrolled genome-wide single nucleotide polymorphism (SNP) array. To cover nearby variants of possible interest, variants within $1 \mathrm{~kb}$ of each candidate gene were also included in the study (table e-2, http://links.lww.com/ NXG/A16).

\section{Imputation}

Imputation was performed using IMPUTE2. ${ }^{27} 1000$ Genomes phase3 data (October 2014 release) supplied by IMPUTE2 were used as the reference panel. Imputation was performed on the same candidate genes as in the SNP array-based analyses and on the 44 previously reported index variants. The whole available Vantaa $85+$ data set $(\mathrm{n}=$ $512)$ was imputed. We have whole-genome sequences of a subset of the Vantaa $85+$ study $(\mathrm{n}=286)$, and we 
compared the imputed genotypes to the whole-genome sequencing-derived genotypes. The median discordance between genotypes was $0.7 \%$, which indicates successful imputation. We performed the same quality control steps and association analyses as we did to the SNP array data, but the genotyping rate threshold was not defined for the 44 index variants.

\section{Statistical analyses}

In the analyses, participants with moderate or frequent CERAD scores were compared with participants with no neuritic plaques (CERAD 0). Similarly, participants with Braak stages 0-II were compared with the high-stage group (Braak stages IV-VI). All participants without CapA $\beta$ were regarded as controls in analyses related to that pathology. The associations between APOE $\varepsilon 4$ allele and neuropathologic features were performed using logistic or linear regression analysis with age and sex as covariates on SPSS (version 23) (table 1). Other statistical analyses were performed using PLINK. Case-control association tests were calculated using logistic regression. Quantitative trait associations were calculated using linear regression. Each regression analysis was performed twice with either age and sex or age, sex, and APOE $\varepsilon 4$ status as covariates. In this candidate gene analysis of GWAS known $\mathrm{AD}$ loci, $p<0.05$ was considered statistically significant.

\section{Standard protocol approvals, registrations, and patient consents}

The Vantaa 85 + study was approved by the Ethics Committee of the Health Centre of the City of Vantaa in 1991 and by the Coordinating Ethics Committee of the Helsinki University Central Hospital in 2014. The Finnish Health and Social Ministry has approved the use of the health and social work records and death certificates. Blood samples were collected only after the participants or their relatives provided written informed consent. The National Authority for Medicolegal

Table 1 Results of association analyses between the $A P O E$ $\varepsilon 4$ allele and neuropathologic features (CERAD, Braak, CAA, and (apA $\beta$ )

\begin{tabular}{llll}
\hline Variable & $\boldsymbol{p}$ Value & OR/ $\boldsymbol{\beta}$ & $\mathbf{9 5 \%} \mathrm{Cl}$ \\
\hline CERAD & $9.25 \mathrm{E}-7$ & 14.91 & $5.07-43.85$ \\
\hline Braak & $2.01 \mathrm{E}-7$ & 8.25 & $3.72-18.27$ \\
\hline CAA & $1.50 \mathrm{E}-8$ & 6.491 & $4.311-8.67$ \\
\hline CapA $\boldsymbol{\beta}$ & $2.13 \mathrm{E}-10$ & 7.54 & $4.04-14.06$
\end{tabular}

Abbreviations: $A P O E$ = apolipoprotein $\mathrm{E} ; \mathrm{CAA}$ = cerebral amyloid angiopathy; CapA $\beta$ = capillary $A \beta ; C I=$ confidence interval; OR = odds ratio.

Univariate logistic (CERAD, Braak, and CapA 3 ) and linear (CAA\%) regression analysis with values adjusted for age at death and sex.

APOE genotyping (rs429358, rs7412).

CERAD/neuritic plaques $=$ moderate or frequent neuritic plaques according to the Consortium to Establish a Registry for Alzheimer Disease vs no neuritic plaques. Braak = Braak stage IV-VI vs Braak stage $0-I I$. CAA = mean percentage of subarachnoid and cortical noncapillary blood vessels with CAA in 6 samples. CapA $\beta=$ capillary $A \beta$ present vs not present.
Affairs (VALVIRA) has approved the collection of the tissue samples at autopsy as well as their use for research. Written informed consent for autopsy was obtained from the nearest relatives.

\section{Results}

\section{SNP array and imputation}

After quality control, 341 variants at 26 candidate loci remained in the SNP array data (table e-2, http://links.lww. com/NXG/A16). There were no variants in EXOC3L2, HLA$D R B 1$, and TREM2 loci. In the imputed data set, 6,038 variants remained in 28 loci after quality control. Imputation was not successful in INPP5D, but it was covered with 26 variants in the SNP array data. Thus, all 29 candidate loci were covered in either the original SNP array or imputed data sets. Imputation of the index variants in $A B C G 1, A P P$, and chromosome 9 region (Chr9 region) was not successful because of too small minor allele frequency or low genotyping quality. Associations between the candidate loci and neuropathologic features are summarized in table 2.

Of the 512 samples, 487 passed the quality control criteria. Samples from 3 individuals were excluded because of difference in reported and estimated sex, 4 because of relatedness of participants, and 18 because of excessive missing data rate or heterozygosity.

\section{Neuropathologic findings}

The characteristics of the whole Vantaa $85+$ sample $(n=512)$ and the neuropathologically and genetically examined subpopulations $(\mathrm{n}=256)$ are shown in table e-1 (http://links.lww. com/NXG/A16). Neuropathologic analysis and data details have been previously reported. ${ }^{19-21}$ No statistically significant differences were found in age at death or sex between the whole study population and the neuropathologically examined subpopulation, but there were slightly more females in the neuropathologically examined subpopulation.

\section{APOE}

As expected and already previously published using other types of analyses, ${ }^{28,29}$ the APOE $\varepsilon 4$ allele was strongly associated with all $\mathrm{AD}$-related neuropathologic features (table 1). Further analyses were performed with and without APOE $\varepsilon 4$ adjustment.

\section{Association of the 29 risk loci with distinct neuropathologic features}

Overall distribution of associations between the 26 candidate loci covered by the SNP array and neuropathologic features are shown in table e-3 (http://links.lww.com/NXG/A16). EXOC3L2, HLA-DRB1, and TREM2 could not be analyzed since there were no variants at these loci in the SNP array. Variant details and $p$ values are shown in table e-4. APOE was treated as a covariate and not included in the list of tested loci. Nine of the 26 SNP array loci were not associated with any histopathologic variables in SNP array data. 
Table 2 Associations of candidate loci with neuropathologic features

\begin{tabular}{|c|c|c|c|c|c|c|c|c|c|}
\hline & CapA $\beta^{a}$ & CapA $\beta^{b}$ & $C A A^{a}$ & $C A A^{b}$ & CERAD $^{a}$ & CERAD $^{b}$ & Braak $^{a}$ & Braak $^{\text {b }}$ & $\begin{array}{l}\text { Variants at } \\
\text { locus (n) }\end{array}$ \\
\hline ABCA7 & & & + & + & + & & + & + & 65 \\
\hline ABCG1 & & & + & + & + & + & + & + & 279 \\
\hline APP & + & + & + & + & & + & + & + & 733 \\
\hline BIN1 & + & + & + & + & + & + & & & 204 \\
\hline CASS4 & & & + & + & & & & & 52 \\
\hline CD2AP & & & + & & & & + & + & 363 \\
\hline CD33 & & & & & & & & & 10 \\
\hline CELF1 & & & & & & & & & 81 \\
\hline CLU & & & + & & & & & & 16 \\
\hline CR1 & & + & + & + & & & + & + & 227 \\
\hline EPHA1 & & & & & & & & & 21 \\
\hline EXOC3L2 & & & & & & & & & 12 \\
\hline FERMT2 & + & + & + & + & + & + & & & 177 \\
\hline GAB2 & & & & + & + & + & + & + & 237 \\
\hline GALNT7 & + & + & + & & & & + & + & 199 \\
\hline HLADRB1 & + & + & + & + & & & & & 66 \\
\hline HLADRB5 & + & & & & & & & & 10 \\
\hline INPP5D & & & & & & & & & 26 \\
\hline MEF2C & + & & & & + & + & + & & 295 \\
\hline MS4A cluster & + & + & + & & + & + & + & + & 714 \\
\hline NME8 & + & + & + & + & + & + & + & + & 270 \\
\hline PICALM & + & & + & + & + & + & & & 400 \\
\hline PTK2B & + & + & & & + & + & + & + & 459 \\
\hline SLC24A4 & & + & + & + & + & + & + & + & 533 \\
\hline SORL1 & + & & + & + & + & + & + & + & 242 \\
\hline Region in chr 9 & + & + & + & + & + & + & + & + & 287 \\
\hline TREM2 & & + & & & & & & & 2 \\
\hline TRIP4 & & & + & + & & & + & + & 49 \\
\hline ZCWPW1 & & & + & + & & & & & 32 \\
\hline
\end{tabular}

Abbreviations: $A P O E$ = apolipoprotein $\mathrm{E} ; \mathrm{CAA}=$ cerebral amyloid angiopathy; $\mathrm{CapA} \beta=$ capillary $\mathrm{A} \beta ; \mathrm{CERAD}=$ Consortium to Establish a Registry for $\mathrm{Alzheimer}$ Disease; $M=$ moderate neuritic plaques; $F=$ frequent neuritic plaques (moderate or frequent) logistic regression analysis vs no neuritic plaques.

Loci with associated variants $(p<0.05)$ marked with "+."

CapAB (CAA type1) logistic regression analysis vs all other participants with ${ }^{\mathrm{a}}$ and without ${ }^{\mathrm{b}}$ APOE $\varepsilon 4$ carrier status; CAA linear regression analysis; Braak stage (IV-VI) logistic regression analysis vs Braak stage (0-II).

After imputation of all 29 loci, associations were found with 24 loci. The 5 loci that did not show association with any neuropathologic feature were CD33, CELF1, EPHA1, EXOC3L2, and INPP5D. We found an association at $p<0.05$ with a neuropathologic feature for 7 of the previously reported 44 index variants, while 9 other variants showed a trend at $0.05<$ $p<0.10$ (table e-5). However, the genotyping rate of index variants was $<95 \%$ for 14 variants.

\section{CERAD score of neuritic plaques}

In the SNP array data, we identified 8 loci that were associated with the CERAD score when adjusted for age at death and sex 
Table 3 Associations in SNP array data between the CERAD score (CERAD score 0 vs M + F) and previously known AD risk loci (341 variants)

\begin{tabular}{|c|c|c|c|c|c|}
\hline CERAD & Rs & $p$ Value $^{a}$ & OR $(95 \% \mathrm{CI})$ & $p$ Value $^{b}$ & OR $(95 \% \mathrm{Cl})$ \\
\hline \multirow[t]{4}{*}{$A B C G 1 \mathrm{chr} 21$} & rs225443 & & & 0.03456 & $1.67(1.04-2.67)$ \\
\hline & rs183436 & 0.01556 & $1.78(1.12-2.84)$ & & \\
\hline & rs225385 & 0.01347 & $0.56(0.35-0.89)$ & 0.02533 & $0.62(0.41-0.94)$ \\
\hline & rs2234718 & 0.01432 & $0.53(0.31-0.88)$ & 0.01775 & $0.56(0.35-0.90)$ \\
\hline FERMT2 chr 14 & rs1112777 & 0.01733 & $0.56(0.35-0.90)$ & & \\
\hline \multirow[t]{11}{*}{ MEF2C chr 5} & rs187270 & 0.003969 & $1.99(1.25-3.18)$ & 0.006607 & $1.82(1.18-2.81)$ \\
\hline & rs190438 & 0.003805 & $2.20(1.29-3.78)$ & 0.003842 & $2.14(1.28-3.58)$ \\
\hline & rs34318 & 0.004267 & $1.98(1.24-3.16)$ & 0.009478 & $1.76(1.15-2.71)$ \\
\hline & rs412458 & 0.0005646 & $3.04(1.62-5.71)$ & 0.0004791 & $3.01(1.62-5.59)$ \\
\hline & rs661311 & 0.0005646 & $3.04(1.62-5.71)$ & 0.0004791 & $3.01(1.62-5.59)$ \\
\hline & rs700591 & 0.02687 & $1.69(1.06-2.68)$ & 0.01942 & $1.66(1.09-2.54)$ \\
\hline & rs700588 & 0.0002122 & $2.67(1.59-4.49)$ & 0.0003895 & $2.40(1.48-3.88)$ \\
\hline & rs160044 & 0.0002684 & $2.62(1.56-4.38)$ & 0.0004573 & $2.37(1.46-3.83)$ \\
\hline & rs10044342 & 0.0008274 & $3.65(1.71-7.79)$ & 0.001522 & $3.27(1.57-6.8)$ \\
\hline & rs3850653 & 0.0304 & $0.54(0.31-0.94)$ & & \\
\hline & rs770463 & 0.02303 & $0.59(0.37-0.93)$ & 0.017 & $0.60(0.40-0.91)$ \\
\hline \multirow[t]{5}{*}{ MS4A chr 11} & rs4939387 & & & 0.03929 & $0.44(0.21-0.96)$ \\
\hline & rs6591595 & 0.03037 & $0.47(0.23-0.93)$ & 0.003674 & $0.38(0.20-0.73)$ \\
\hline & rs2847212 & 0.04648 & $0.51(0.27-0.99)$ & 0.008148 & $0.44(0.24-0.81)$ \\
\hline & rs4939416 & 0.04648 & $0.51(0.27-0.99)$ & 0.008148 & $0.44(0.24-0.81)$ \\
\hline & rs474347 & & & 0.007831 & $0.44(0.24-0.81)$ \\
\hline \multirow[t]{7}{*}{ PICALM chr11 } & rs2077815 & 0.04248 & $0.55(0.31-0.98)$ & & \\
\hline & rs10501604 & 0.0108 & $2.41(1.23-4.74)$ & 0.04079 & $1.98(1.03-3.80)$ \\
\hline & rs713346 & 0.02167 & $1.98(1.11-3.55)$ & & \\
\hline & rs475639 & 0.01235 & $1.77(1.13-2.76)$ & & \\
\hline & rs680119 & 0.013 & $0.58(0.38-0.89)$ & & \\
\hline & rs642949 & 0.04878 & $1.63(1.00-2.66)$ & & \\
\hline & rs10501608 & 0.01042 & $2.42(1.23-4.76)$ & 0.03225 & $2.05(1.06-3.94)$ \\
\hline \multirow[t]{6}{*}{ PTK2 chr 8} & rs2322606 & 0.01452 & $2.34(1.18-4.61)$ & 0.0109 & $2.30(1.21-4.37)$ \\
\hline & rs10097861 & 0.01611 & $2.20(1.16-4.20)$ & 0.01598 & $2.12(1.15-3.91)$ \\
\hline & rs1879188 & 0.007295 & $2.43(1.27-4.65)$ & 0.02249 & $2.01(1.10-3.65)$ \\
\hline & rs1879189 & 0.007295 & $2.43(1.27-4.65)$ & 0.02249 & $2.01(1.10-3.65)$ \\
\hline & rs3735759 & 0.01496 & $2.43(1.19-4.95)$ & 0.02571 & $2.17(1.10-4.28)$ \\
\hline & rs4733058 & 0.0406 & $0.55(0.31-0.98)$ & 0.02569 & $0.55(0.33-0.93)$ \\
\hline
\end{tabular}


Table 3 Associations in SNP array data between the CERAD score (CERAD score 0 vs M + F) and previously known AD risk loci (341 variants) (continued)

\begin{tabular}{|c|c|c|c|c|c|}
\hline CERAD & Rs & $p$ Value $^{a}$ & OR $(95 \% \mathrm{Cl})$ & $p$ Value $^{b}$ & OR $(95 \% \mathrm{Cl})$ \\
\hline SLC24A4 chr 14 & rs11623019 & 0.04134 & $0.58(0.35-0.98)$ & 0.03965 & $0.61(0.37-0.97)$ \\
\hline SORL1 chr 11 & rs2298525 & 0.01498 & $0.37(0.17-0.82)$ & 0.02715 & $0.45(0.22-0.91)$ \\
\hline
\end{tabular}

Abbreviations: $A P O E$ = apolipoprotein $\mathrm{E} ; \mathrm{CERAD}=$ Consortium to Establish a Registry for Alzheimer Disease; $\mathrm{Cl}=$ confidence interval; $\mathrm{M}=$ moderate neuritic plaques; $\mathrm{F}=$ frequent neuritic plaques (moderate or frequent, $\mathrm{n}=171$ ) vs CERAD (no neuritic plaques, $\mathrm{n}=65$ ); OR = odds ratio; SNP = single nucleotide polymorphism.

Binary logistic regression analysis with and without adjustment for $A P O E \& 4$.

Binary logistic regression analysis adjusted for age at death and sex and with ${ }^{\mathrm{a}}$ and without $^{\mathrm{b}}$ carrier status of the APOE $\varepsilon 4$ allele.

All variants with $p<0.05$ are shown.

but not for APOE $\varepsilon 4$ (table 3). When APOE $\varepsilon 4$ was included as a covariate, all these associations remained significant, and an additional association was detected with FERMT2 (rs1112777, $p=0.01733$, odds ratio [OR] $0.5587,95 \%$ confidence interval $[\mathrm{CI}]$ 0.35-0.90). The strongest association was found between the CERAD score and the MEF2Clocus (rs700588) (when adjusted with age, sex, and APOE $\varepsilon 4$, $p=0.0002122$, OR 2.67, 95\% CI 1.59-4.49 and without APOE $\varepsilon 4 p=0.0003895$, OR 2.40, 95\% CI 1.48-3.88). $M E F 2 C$ did not associate with any other histopathologic variables (Braak, CAA, and CapA $\beta$ ).

In the imputed data, we identified 14 loci that were associated with the CERAD score (table 2, tables e- 6 and e-7, http://links.lww.com/NXG/A16). The strongest association found was the same as in the SNP array data: rs700588 at MEF2C.

\section{Braak stage}

In the SNP array data, 6 loci were associated with a high Braak stage (IV-VI vs 0-II) (APP, GALNT7, PTK2B, SLC24A, SORL1, and TRIP4), and when adjusted for APOE $\varepsilon 4$, associations were also found with $A B C G 1$ (table 4). Overall, the associations with the Braak stage were weaker than those with the CERAD score. The strongest association was found with ABCG1 (rs532345, $p=0.02671$, OR 0.5571, 95\% CI 0.33-0.93 with APOE $\varepsilon 4$ adjustment).

In the imputed data, we identified 15 loci that showed association with the Braak stage ( $A B C A 7, A B C G 1, A P P, C D 2 A P$,

Table 4 Associations in SNP array data between the Braak stage and previously known AD risk loci (341 variants) comparing participants with Braak stage IV-VI $(n=119)$ vs Braak stage $0-I I(n=74)$

\begin{tabular}{|c|c|c|c|c|c|}
\hline Braak & Rs & $p$ Value $^{a}$ & OR $(95 \% \mathrm{CI})$ & $p$ Value $^{b}$ & OR $(95 \% \mathrm{Cl})$ \\
\hline \multirow[t]{3}{*}{$A B C G 1 \mathrm{chr} 21$} & Rs225443 & 0.0267 & $0.57(0.34-0.94)$ & & \\
\hline & Rs532345 & 0.02671 & $0.56(0.33-0.93)$ & & \\
\hline & Rs691687 & 0.04217 & $0.59(0.35-0.98)$ & & \\
\hline \multirow[t]{2}{*}{ APP chr 21} & Rs400603 & & & 0.04806 & $0.42(0.18-0.99)$ \\
\hline & Rs2830104 & 0.04174 & $1.93(1.03-3.62)$ & & \\
\hline GALNT7 chr 4 & Rs7658148 & & & 0.03616 & $0.63(0.41-0.97)$ \\
\hline \multirow[t]{4}{*}{ PTK2b chr 8} & Rs2322606 & 0.04005 & $1.96(1.03-3.73)$ & 0.02477 & $1.96(1.09-3.52)$ \\
\hline & Rs10097861 & 0.04979 & $1.84(1.00-3.40)$ & & \\
\hline & Rs1879188 & 0.033 & $1.94(1.06-3.57)$ & & \\
\hline & Rs1879189 & 0.033 & $1.94(1.06-3.57)$ & & \\
\hline SLC24A4 chr14 & Rs2402130 & 0.02 & $2.24(1.12-4.46)$ & 0.03353 & $1.99(1.06-3.76)$ \\
\hline SORL1 chr 11 & Rs1532763 & 0.048 & $0.59(0.35-1.00)$ & 0.0324 & $0.60(0.37-0.96)$ \\
\hline TRIP4 chr15 & Rs936689 & & & 0.03045 & $2.24(1.08-4.66)$ \\
\hline
\end{tabular}

Abbreviations: $\mathrm{AD}=$ Alzheimer disease; $\mathrm{APOE}=$ apolipoprotein $\mathrm{E} ; \mathrm{Cl}=$ confidence interval; $\mathrm{OR}=$ odds ratio; $\mathrm{SNP}=$ single nucleotide polymorphism. Binary logistic regression analysis with and without adjustment for $A P O E \varepsilon 4$.

Binary logistic regression analysis adjusted for age at death and sex and with ${ }^{\mathrm{a}}$ and without ${ }^{\mathrm{b}}$ carrier status of the $A P O E \varepsilon 4$ allele for 341 variants. All variants with $p<0.05$ are shown. 
Chr9 region, CR1, GAB2, GALNT7, MEF2C, MS4A, NME8, PTK2B, SLC24A4, SORL1, and TRIP4) (table 2, tables e-8 and e-9, http://links.lww.com/NXG/A16). All except for $M E F 2 C$ showed association regardless of APOE $\varepsilon 4$ adjustment. Rs 2512518 at $G A B 2$ locus had the strongest association ( $p=0.004372$, OR $0.31,95 \%$ CI $0.14-0.69)$ when adjusted for age and sex.

\section{CAA}

In the SNP array data, 7 loci were associated with CAA (ABCA7, CR1, FERMT2, NME8, SLC24A4, SORL1, and ZCWPW1), and when adjusted for APOE $\varepsilon 4$, an additional locus (GALNT7) was found (table 5). The strongest association was with $C R 1$ (rs65087, $p=0.004934, \beta 2.52$, 95\% CI 0.78-4.26 without APOE $\varepsilon 4$ adjustment); $C R 1$ and $A B C A 7$ were not associated with any other histopathologic variable than CAA.
In the imputed data, we identified 20 loci that were associated with CAA (table 2, tables e-10 and e-11, http://links.lww. $\mathrm{com} / \mathrm{NXG} / \mathrm{A} 16)$. Fifteen loci were associated regardless of $A P O E \varepsilon 4$ adjustment (ABCA7, ABCG1, APP, BIN1, CASS4, Chr9 region, CR1, FERMT2, HLA-DRB1, NME8, PICALM, SLC24A4, SORL1, TRIP4, and ZCWPW1), 4 loci when adjusted for age, sex, and APOE $\varepsilon 4$ (CD2AP, CLU, GALNT7, and MS4A locus) and 1 locus (GAB2) when adjusted for age and sex. The strongest association was found for rs 185310342 at $C R 1$ locus $(p=7.17 \mathrm{E}-07, \beta 14.4,95 \%$ CI $8.88-20)$ when adjusted for age and sex.

\section{СарAß}

In SNP array data, 4 loci were associated with CapA $\beta$ ( $A P P$, $B I N 1, M S 4 A$, and $P T K 2 B$ ), and when adjusted for APOE $\varepsilon 4$, age, and sex, 3 additional loci were associated with CapA $\beta$ (GALNT7, NME8, and FERMT2, table 6). The strongest

Table 5 Associations in SNP array data between CAA and previously known AD risk loci (341 variants) adjusted for age at death and sex and with and without carrier status of the APOE $\varepsilon 4$ allele

\begin{tabular}{|c|c|c|c|c|c|}
\hline CAA & Rs & $p$ Value $^{a}$ & $\beta(95 \% \mathrm{Cl})$ & $p$ Value $^{b}$ & $\beta(95 \% \mathrm{Cl})$ \\
\hline \multirow[t]{2}{*}{$A B C A 7$ chr 19} & rs3752240 & 0.007962 & $-1.97(-3.41$ to -0.53$)$ & 0.01813 & $-1.86(-3.38$ to -0.33$)$ \\
\hline & rs2279796 & 0.04255 & $1.44(0.06$ to 2.82$)$ & & \\
\hline \multirow[t]{6}{*}{ CR1 chr 1} & rs11117959 & 0.03422 & $1.83(0.15$ to 3.52$)$ & 0.004963 & 2.53 (0.78 to 4.27$)$ \\
\hline & rs650877 & 0.03592 & 1.81 (0.13 to 3.49$)$ & 0.004934 & 2.52 (0.78 to 4.26$)$ \\
\hline & rs11118131 & 0.03592 & 1.81 (0.13 to 3.49$)$ & 0.004934 & 2.52 (0.78 to 4.26$)$ \\
\hline & rs677066 & & & 0.01169 & 2.09 (0.48 to 3.70$)$ \\
\hline & rs6691117 & & & 0.01169 & 2.09 (0.48 to 3.70$)$ \\
\hline & rs12734030 & & & 0.03786 & 1.95 (0.12 to 3.78$)$ \\
\hline \multirow[t]{2}{*}{ FERMT2 chr14 } & rs8007536 & 0.008585 & 3.29 (0.86 to 5.72$)$ & 0.04077 & 2.701 (0.13 to 5.28$)$ \\
\hline & rs4901318 & 0.009914 & 2.79 (0.69 to 4.89$)$ & 0.04571 & 2.28 (0.05 to 4.50$)$ \\
\hline GALNT7 chr 4 & rs10001613 & 0.04873 & $-1.46(-2.90$ to -0.02$)$ & & \\
\hline NME8 chr 7 & rs2722301 & 0.01244 & $2.13(0.47$ to 3.79$)$ & 0.01564 & 2.18 (0.42 to 3.93$)$ \\
\hline \multirow[t]{3}{*}{ SLC24A4 chr 14} & rs4904896 & 0.03997 & $-1.51(-2.95$ to -0.08$)$ & 0.01082 & \\
\hline & rs4904903 & & & 0.03422 & $-1.90(-3.64$ to -0.15$)$ \\
\hline & rs10498633 & 0.04763 & 1.78 (0.03 to 3.53$)$ & 0.04017 & 1.946 (0.10 to 3.80$)$ \\
\hline \multirow[t]{4}{*}{ SORL1 chr 11} & rs661057 & 0.02727 & $-1.74(-3.27$ to -0.20$)$ & & \\
\hline & rs676759 & 0.04524 & $-1.54(-3.04$ to -0.04$)$ & & \\
\hline & rs666004 & 0.03078 & $-1.62(-3.08$ to -0.16$)$ & 0.01868 & $-1.86(-3.40$ to -0.32$)$ \\
\hline & rs3781827 & 0.01306 & 1.87 (0.40 to 3.33$)$ & 0.008359 & 2.09 (0.55 to 3.64$)$ \\
\hline ZCWPW1 chr 7 & rs5015756 & 0.009438 & $-1.89(-3.31$ to -0.47$)$ & 0.02247 & $-1.76(-3.26$ to -0.26$)$ \\
\hline
\end{tabular}

Abbreviations: $\mathrm{AD}=$ Alzheimer disease; $A P O E=$ apolipoprotein $\mathrm{E} ; \mathrm{CAA}=$ cerebral amyloid angiopathy; $\mathrm{Cl}=\mathrm{confidence}$ interval; $\mathrm{OR}=$ odds ratio; $\mathrm{SNP}=$ single nucleotide polymorphism.

The severity of CAA is expressed using the percentage of blood vessels with CAA of all blood vessels visible in the tissue slide.

Linear regression analysis adjusted for age at death and sex and with ${ }^{\mathrm{a}}$ and without $^{\mathrm{b}}$ carrier status of the $A P O E 4$ allele for 341 variants $(\mathrm{N}=256$ ).

All variants with $p<0.05$ are shown. 
Table 6 Associations in SNP array data between CapA $\beta$ and previously known AD risk loci (341 variants)

\begin{tabular}{|c|c|c|c|c|c|}
\hline СарA $\beta$ & Rs & $p$ Value $^{a}$ & OR $(95 \% \mathrm{Cl})$ & $p$ Value $^{b}$ & OR $(95 \% \mathrm{Cl})$ \\
\hline \multirow[t]{6}{*}{ APP chr 21} & Rs1783016 & 0.005933 & $2.01(1.22-3.30)$ & 0.02242 & $1.67(1.08-2.61)$ \\
\hline & Rs214488 & 0.0259 & $0.52(0.29-0.92)$ & & \\
\hline & Rs383700 & 0.03333 & $0.34(0.13-0.92)$ & 0.0479 & $0.40(0.16-0.99)$ \\
\hline & Rs2014146 & 0.03392 & $0.61(0.38-0.96)$ & & \\
\hline & Rs2830000 & 0.02793 & $0.53(0.30-0.93)$ & & \\
\hline & \multicolumn{2}{|l|}{ Rs466609 } & & 0.03013 & $0.40(0.18-0.92)$ \\
\hline BIN1 chr 2 & Rs873270 & 0.01358 & $0.43(0.22-0.84)$ & 0.01855 & $0.54(0.31-0.97)$ \\
\hline \multirow[t]{2}{*}{ FERMT2 chr 14} & Rs1112777 & 0.04187 & $0.62(0.39-0.98)$ & & \\
\hline & Rs7494379 & 0.01501 & $1.78(1.12-2.83)$ & & \\
\hline \multirow[t]{3}{*}{ GALNT7 chr 4} & Rs2332655 & 0.03211 & $0.62(0.39-0.96)$ & & \\
\hline & Rs10001613 & 0.01362 & $0.57(0.36-0.89)$ & & \\
\hline & Rs12644699 & 0.04208 & $0.56(0.32-0.98)$ & & \\
\hline \multirow[t]{2}{*}{ MS4A chr 11} & \multicolumn{3}{|l|}{ Rs2847212 } & 0.04211 & $0.47(0.23-0.97)$ \\
\hline & \multicolumn{3}{|l|}{ Rs4939416 } & 0.04211 & $0.47(0.23-0.97)$ \\
\hline NME8 chr 7 & Rs10488617 & 0.04465 & $0.58(0.34-0.99)$ & & \\
\hline PTK2b chr 8 & Rs6986075 & 0.02349 & $1.67(1.07-2.59)$ & 0.027 & $1.60(1.09-2.34)$ \\
\hline \multicolumn{6}{|c|}{$\begin{array}{l}\text { Abbreviations: } A D=\text { Alzheimer disease; } A P O E=\text { apolipoprotein } \mathrm{E} ; \mathrm{CapA} \beta=\text { capillary } \mathrm{A} \beta ; \mathrm{Cl}=\text { confidence interval; } \mathrm{OR}=\text { odds ratio; SNP = single nucleotide } \\
\text { polymorphism. } \\
\text { Comparison between participants with } \mathrm{CapA} \beta(\mathrm{n}=77) \text { and all other participants }(\mathrm{n}=179) \text { using binary logistic regression analysis. } \\
\text { Binary logistic regression analysis adjusted for age at death and sex and with }{ }^{\mathrm{a}} \text { and } \text { without }^{\mathrm{b}} \text { carrier status of the } A P O E \varepsilon 4 \text { allele for } 341 \text { variants. } \\
\text { All variants with } p<0.05 \text { are shown. }\end{array}$} \\
\hline
\end{tabular}

association was found with APP (rs1783016, $p=0.005933$, OR 2.01, 95\% CI 1.22-3.30 with APOE $\varepsilon 4$ adjustment).

In imputed data, we found association for 15 loci (table 2, tables e-12 and e-13, http://links.lww.com/NXG/A16). Of these, 9 were associated regardless of $A P O E \varepsilon 4$ adjustment (APP, BIN1, FERMT2, GALNT7, HLA-DRB1, MS4A, NME8, $P T K 2 B$, and Chr9 region), 3 loci (MEF2C, PICALM, and SORL1) when adjusted for age, sex, and $A P O E \varepsilon 4$, and 3 loci (CR1, SLC24A4, and TREM2) when adjusted for age and sex. The strongest association was found for rs66962766 at HLADRB1 locus ( $p=0.002594$, OR $0.54,95 \%$ CI $0.37-0.81$ ).

\section{Discussion}

In this study, we focused on previously reported genetic $\mathrm{AD}$ risk loci identified in GWAS analyses on clinically or neuropathologically verified patients with $\mathrm{AD}$ and controls. We confirmed the association of 24 of the 29 previously known $\mathrm{AD}$ risk loci with one or more $\mathrm{AD}$-related neuropathologic features (CERAD, Braak, CAA, and CapA $\beta$ ) (table 2).

In this study, we found strong associations between $A P O E \varepsilon 4$ and all $\mathrm{AD}$-related neuropathologic features (CERAD, Braak, CAA, and $\operatorname{CapA} \beta$, table 1$)$. This is in line with previous studies. ${ }^{4,21}$ To take into account the strong effect of APOE on the other loci, ${ }^{30}$ we performed analyses in 2 ways, testing each neuropathologic feature with and without the adjustment for the $A P O E \& 4$ carrier status. Previously, certain loci have been reported to be more likely influenced by $A P O E \varepsilon 4$ than others; e.g., PICALM and EXOC $3 L 2$ have been found to show stronger associations with neuropathologically confirmed $\mathrm{AD}$ without $A P O E$ \&4 adjustment, whereas adjustment with $A P O E$ was reported to have no effect on the association between $C R 1$, $C L U$, or BIN1 and neuropathologic $\mathrm{AD} .{ }^{30}$ We found that the $A P O E$ adjustment did not remarkably alter the associations between neuropathologic features in most loci (table 2).

In addition to $A P O E, A P P$, Chr9 region, NME8, PICALM, and SLC24A4 were associated with all neuropathologic variables (CERAD, Braak, CAA, and CapA $\beta$ ) (table 2).

On the other hand, certain loci were associated only with specific neuropathologic features. CASS4, CLU, and ZCWPW1 were associated only with CAA. TREM2 and HLA$D R B 5$ were associated with only CapA $\beta$, whereas HLA-DRB1 was associated with both CAA and CapA $\beta$ but not with other pathologies (table 2). These are interesting findings suggesting that the risk loci (and mechanisms) for CAA and CapA $\beta$ may be partially distinct. It is of note that there has 
been only 1 previous GWAS that investigated the genetic background of CAA, in which the only significant association was found between CAA and the APOE locus. ${ }^{4}$ However, in a previous candidate gene analysis, $C R 1$ was associated with CAA pathology burden. ${ }^{31}$ The association between CAA and CR1 was confirmed in our study. No previous GWAS has been performed using CapA $\beta$ as the phenotype. Here, we reported significant associations between CapA $\beta$ and 15 loci (APP, BIN1, Chr9 region, CR1, FERMT2, GALNT7, HLADRB1, MEF2C, MS4A, NME8, PICALM, PTK2B, SLC24A4, $S O R L 1$, and TREM2). Our results provide information on the partly shared and partly distinct genetic backgrounds of $\mathrm{AD}$ related neuropathologic features.

\section{Author contributions}

Mira Mäkelä and Karri Kaivola: acquisition of data, analysis and interpretation of data, and drafting the manuscript. Miko Valori: acquisition of data and analysis and interpretation of data. Anders Paetau and Tuomo Polvikoski: acquisition of data and critical revision of the manuscript for intellectual content. Andrew B. Singleton: acquisition of data and analysis and interpretation of data. Bryan J. Traynor: acquisition of data and critical revision of the manuscript for intellectual content. David J. Stone and Terhi Peuralinna: acquisition of data and analysis and interpretation of data. Pentti J. Tienari: analysis and interpretation of data, study concept, and design and critical revision of the manuscript for intellectual content. Tanskanen Maarit: acquisition of data and critical revision of the manuscript for intellectual content. Liisa Myllykangas: analysis and interpretation of data, supervision, study concept and design, and critical revision of the manuscript for intellectual content.

\section{Acknowledgment}

The authors thank Dr. Leena Niinistö and Prof. emeritus Raimo Sulkava for establishing the Vantaa 85+ Study and Merja Haukka for technical assistance.

\section{Study funding}

The study was supported by the Helsinki University Central Hospital competitive research fund, the Academy of Finland (294817), the Finska Läkaresälskapet, and in part by the Intramural Research Program of the NIH, National Institute on Ageing (Z01-AG000949-02). The whole-genome sequencing of Vantaa85+ was funded by Merck \& Co., Inc., Kenilworth, NJ USA, and Intramural Research Program of the NIH. David Stone is employed by Merck \& Co., Inc., West Point, PA, USA.

\section{Disclosure}

M. Mäkelä has served on the editorial board of the Journal of Alzheimer's Disease and has received research support from Helsinki University. K. Kaivola has received research support from the Finnish Medical Foundation and the Maire Taponen Foundation. M. Valori is an employee of Blueprint Genetics. A. Paetau and T. Polvikoski report no disclosures. A.B. Singleton has received travel funding from 23andMe; serves on the editorial boards of Annals of Neurology, Lancet Neurology,
Neurogenetics, Neurodegenerative Diseases, Brain, and the Journal of Parkinson's Disease; holds a patent (pending) for Panel of markers to diagnose stroke; and has received research support from the NIH and the Department of Defense. B.J. Traynor has received travel funding from the Italian Football Federation (FIGC), American Academy of Neurology, Cold Spring Harbor Laboratories, the Italian ALS Association (ARISLA), Movement Disorders Society, Wellcome Trust, the Finnish Neurological Society, the NorthEast ALS Consortium (NEALS), UC Irivine, the ALS Hope Foundation, the ALS Association, the American Academy of Neurology, the Motor Neuron Association (United Kingdom), Microsoft Research, the Italian Neurological Society, the University of Toronto, the International Congress of Human Genetics, and the Society for Neuroscience; has served on the editorial boards of Neurology ${ }^{\circledR}$, Journal of Neurology, Neurosurgery, and Psychiatry (JNNP), Neurobiology of Aging, and JAMA Neurology; holds a patent (pending in Europe and the United States) on Clinical testing and therapeutic intervention for the hexanucleotide repeat expansion of the C9ORF72 gene; is employed by the NIH; and has received research support from Merck Inc., Intramural Research Program of the NIH, the Myasthenia Gravis Foundation, the ALS Association, the Packard Center for ALS Research, FIGC (The Italian Football Federation), the Center for Disease Control and Prevention, Microsoft Research, the Italian ALS Association (ARISLA), and the Muscular Dystrophy Association. D.J. Stone is employed by Merck \& Co. T. Peuralinna reports no disclosures. P.J. Tienari has received travel funding from TEVA, Merck (Europe), Biogen, SanofiGenzyme, and Novartis; has received speaker honoraria from Biogen, Merck (Europe), TEVA, Novartis, SanofiGenzyme, Orion, Roche, and Pfizer; coholds a patent (pending) on Genetic testing and of Hexanucleotide repeat expansion of C9orf72 implicated in amyotrophic lateral sclerosis (ALS) and frontotemporal dementia (FTD); has received research support from Biogen Finland, Roche, Novartis Finland, Sanofi-Genzyme, Merck \& Co Inc. (United States), and Helsinki University Hospital. M. Tanskanen reports no disclosures. L. Myllykangas serves on the editorial board of the Journal of Alzheimer's Disease. Funding information and disclosures are provided at the end of the article. Full disclosure form information provided by the authors is available with the full text of this article at Neurology.org/NG.

Received May 13, 2017. Accepted in final form November 26, 2017.

\section{References}

1. Gatz M, Reynolds CA, Fratiglioni L, et al. Role of genes and environments for explaining Alzheimer disease. Arch Gen Psychiatry 2006;63:168-174.

2. Saunders AM, Strittmatter WJ, Schmechel D, et al. Association of apolipoprotein E allele epsilon 4 with late-onset familial and sporadic Alzheimer's disease. Neurology 1993;43:1467-1472.

3. Meyer JM, Breitner JC. Multiple threshold model for the onset of Alzheimer's disease in the NAS-NRC twin panel. Am J Med Genet 1998;81:92-97.

4. Beecham GW, Hamilton K, Naj AC, et al. Genome-wide association meta-analysis of neuropathologic features of Alzheimer's disease and related dementias. PLoS Genet 2014;10:e1004606.

5. Bertram L, McQueen MB, Mullin K, Blacker D, Tanzi RE. Systematic meta-analyses of Alzheimer disease genetic association studies: the AlzGene database. Nat Genet 2007;39:17-23. 
6. Lambert JC, Heath S, Even G, et al. Genome-wide association study identifies variants at CLU and CR1 associated with Alzheimer's disease. Nat Genet 2009;41:1094-1099.

7. Harold D, Abraham R, Hollingworth P, et al. Genome-wide association study identifies variants at CLU and PICALM associated with Alzheimer's disease. Nat Genet 2009;41:1088-1093.

8. Lambert JC, Ibrahim-Verbaas CA, Harold D, et al. Meta-analysis of 74,046 individuals identifies 11 new susceptibility loci for Alzheimer's disease. Nat Genet 2013;45:1452-1458.

9. Hollingworth P, Harold D, Sims R, et al. Common variants at ABCA7, MS4A6A/ MS4A4E, EPHA1, CD33 and CD2AP are associated with Alzheimer's disease. Nat Genet 2011;43:429-435.

10. Seshadri S, Fitzpatrick AL, Ikram MA, et al. Genome-wide analysis of genetic loci associated with Alzheimer disease. JAMA 2010;303:1832-1840.

11. Guerreiro R, Wojtas A, Bras J, et al. TREM2 variants in Alzheimer's disease. N Engl J Med 2013;368:117-127.

12. Chapuis J, Hansmannel F, Gistelinck M, et al. Increased expression of BIN1 mediates Alzheimer genetic risk by modulating tau pathology. Mol Psychiatry 2013;18:1225-1234.

13. Holler CJ, Davis PR, Beckett TL, et al. Bridging integrator 1 (BIN1) protein expression increases in the Alzheimer's disease brain and correlates with neurofibrillary tangle pathology. J Alzheimers Dis 2014;42:1221-1227.

14. Reiman EM, Webster JA, Myers AJ, et al. GAB2 alleles modify Alzheimer's risk in APOE epsilon4 carriers. Neuron 2007;54:713-720.

15. Wang W, Mutka AL, Zmrzljak UP, et al. Amyloid precursor protein alpha- and betacleaved ectodomains exert opposing control of cholesterol homeostasis via SREBP2. FASEB J 2014;28:849-860.

16. Shulman JM, Chen K, Keenan BT, et al. Genetic susceptibility for Alzheimer disease neuritic plaque pathology. JAMA Neurol 2013;70:1150-1157.

17. Braak H, Braak E. Staging of Alzheimer's disease-related neurofibrillary changes. Neurobiol Aging 1995;16:271-278; discussion 278-284.

18. Mirra SS, Heyman A, McKeel D, et al. The consortium to establish a registry for Alzheimer's disease (CERAD). part II. standardization of the neuropathologic assessment of Alzheimer's disease. Neurology 1991;41:479-486.

19. Polvikoski T, Sulkava R, Myllykangas L, et al. Prevalence of Alzheimer's disease in very elderly people: a prospective neuropathological study. Neurology 2001;56:1690-1696.
20. Tanskanen M, Makela M, Myllykangas L, et al. Prevalence and severity of cerebra amyloid angiopathy: a population-based study on very elderly Finns (Vantaa 85+). Neuropathol Appl Neurobiol 2012;38:329-336.

21. Makela M, Paetau A, Polvikoski T, Myllykangas L, Tanskanen M. Capillary amyloidbeta protein deposition in a population-based study (Vantaa $85+$ ). J Alzheimers Dis 2016;49:149-157.

22. Myllykangas L, Polvikoski T, Sulkava R, et al. Genetic association of alpha2 macroglobulin with Alzheimer's disease in a Finnish elderly population. Ann Neurol 1999;46:382-390.

23. Peuralinna T, Myllykangas L, Oinas M, et al. Genome-wide association study of neocortical Lewy-related pathology. Ann Clin Transl Neurol 2015;2:920-931.

24. Purcell S, Neale B, Todd-Brown K, et al. PLINK: a tool set for whole-genome association and population-based linkage analyses. Am J Hum Genet 2007;81: 559-575.

25. Chang CC, Chow CC, Tellier LC, Vattikuti S, Purcell SM, Lee JJ. Second-generation PLINK: rising to the challenge of larger and richer datasets. Gigascience 2015;4:7. eCollection 2015.

26. Anderson CA, Pettersson FH, Clarke GM, Cardon LR, Morris AP, Zondervan KT Data quality control in genetic case-control association studies. Nat Protoc 2010;5: $1564-1573$.

27. Howie BN, Donnelly P, Marchini J. A flexible and accurate genotype imputation method for the next generation of genome-wide association studies. PLoS Genet 2009; 5:e1000529.

28. Polvikoski T, Sulkava R, Haltia M, et al. Apolipoprotein E, dementia, and cortical deposition of beta-amyloid protein. N Engl J Med 1995;333:1242-1247.

29. Peuralinna T, Tanskanen M, Makela M, et al. APOE and AbetaPP gene variation in cortical and cerebrovascular amyloid-beta pathology and Alzheimer's disease: a population-based analysis. J Alzheimers Dis 2011;26:377-385.

30. Wijsman EM, Pankratz ND, Choi Y, et al. Genome-wide association of familial lateonset Alzheimer's disease replicates BIN1 and CLU and nominates CUGBP2 in interaction with APOE. PLoS Genet 2011;7:e1001308.

31. Biffi A, Shulman JM, Jagiella JM, et al. Genetic variation at CR1 increases risk of cerebral amyloid angiopathy. Neurology 2012;78:334-341. 


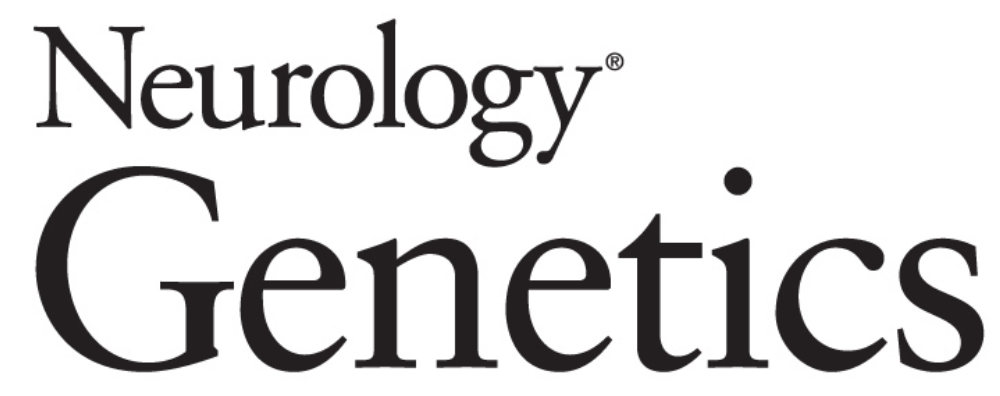

\section{Alzheimer risk loci and associated neuropathology in a population-based study (Vantaa 85+) \\ Mira Mäkelä, Karri Kaivola, Miko Valori, et al. \\ Neurol Genet 2018;4; \\ DOI 10.1212/NXG.0000000000000211}

This information is current as of January 18, 2018

\section{Updated Information \& Services}

References

Citations

Subspecialty Collections

Permissions \& Licensing

Reprints including high resolution figures, can be found at: http://ng.neurology.org/content/4/1/e211.full.html

This article cites 31 articles, 0 of which you can access for free at: http://ng.neurology.org/content/4/1/e211.full.html\#\#ref-list-1

This article has been cited by 2 HighWire-hosted articles: http://ng.neurology.org/content/4/1/e211.full.html\#\#otherarticles

This article, along with others on similar topics, appears in the following collection(s):

Alzheimer's disease

http://ng.neurology.org//cgi/collection/alzheimers_disease

Cohort studies

http://ng.neurology.org//cgi/collection/cohort_studies

Information about reproducing this article in parts (figures,tables) or in its entirety can be found online at:

http://ng.neurology.org/misc/about.xhtml\#permissions

Information about ordering reprints can be found online: http://ng.neurology.org/misc/addir.xhtml\#reprintsus

Neurol Genet is an official journal of the American Academy of Neurology. Published since April 2015, it is an open-access, online-only, continuous publication journal. Copyright Copyright $\odot 2018$ The Author(s). Published by Wolters Kluwer Health, Inc. on behalf of the American Academy of Neurology.. All rights reserved. Online ISSN: 2376-7839.

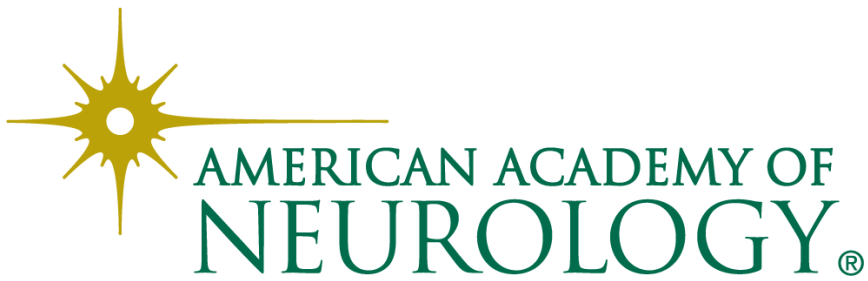

